\title{
Validation of the Nurses' Involvement in Dying Patients and Family Care-Korean Version
}

\author{
Mi Yeon Kim, R.N., Hanna Lee, R.N., Inyoung Lee, R.N., \\ Mirim Lee, R.N. and Haeryun Cho, R.N., Ph.D. \\ Department of Nursing, Wonkwang University, Iksan, Korea
}

Purpose: The purpose of this study was to test the validity of the Korean version of the Nurses' Involvement in Dying Patients and Family Care (NIDPFC) instrument. Methods: Data were collected from 410 registered nurses at a university hospital, general hospitals, and a convalescent hospital. Data were collected from June 23 to July 17, 2020. Internal consistency reliability, construct validity, and criterion validity were examined using the SPSS and AMOS software. Results: Of the 35 preliminary items of the instrument, 24 items were finally selected after evaluating the content validity, analyzing the items, and assessing construct validity. The following four factors were derived: "burden" (seven items), "deep involvement" (eight items), "resilience" (five items), and "empathy" (four items), with a cumulative explanatory variance of $55.2 \%$. For criterion validity, a significant positive relationship was found between the NIDPFC and attitudes toward caring for the dying. For internal consistency reliability, the Cronbach's $\alpha$ was 0.82 . Conclusion: The validity and reliability of the NIDPFC were verified. Therefore, the NIDPFC is an effective instrument to use in further studies.

Key Words: Empathy, Family, Hospices, Nurses
Received August 7, 2020

Revised October 4, 2020

Accepted October 19, 2020

\section{Correspondence to}

Hanna Lee

ORCID:

https://orcid.org/0000-0001-6084-262X

E-mail: tjfdlrwo@naver.com

\section{INTRODUCTION}

According to mortality statistics from 2018, among the 298,900 people who died in South Korea, 227,761 (76.2\%) died in a hospital [1]. Since the proportion of people who die at medical facilities is high, the role of nurses who care for $\mathrm{dy}$ ing patients is important. Specifically, for patients who are in the dying process and their family members to experience a comfortable and meaningful death, nurses should have an appropriate understanding of death and attitudes toward caring for dying patients [2]. Nurses should provide holistic care that satisfies physical, psychological, social, and spiritual needs so that patients who face death and their family members can live dignified and high-quality lives during their remaining time and can prepare for a peaceful death [3]. The goal when caring for dying patients and their family is to support the highest possible quality of life among patients in the dying process and their family members and to help patients in the dying stage to maintain dignity and prepare for a comfortable death $[3,4]$.

The crisis situation when little time remains in a patient's life has a heavy impact both on patients and their family members. The family members of patients experience severe stress when confronted with the death of a family member and the burden of caring for the dying patient [5,6]. In particular, when providing care for a dying patient, the family's entire attention is focused on the patient, so family members prioritize the patient

This is an Open Access article distributed under the terms of the Creative Commons Attribution Non-Commercial License (http://creativecommons.org/licenses/by-nc/4.0/) which permits unrestricted non-commercial use, distribution, and reproduction in any medium, provided the original work is properly cited. 
over themselves. The personal desires and sadness of family members are pushed aside, and as the patient deteriorates, the health problems of family members increase [6]. Therefore, nurses should pay attention to family care by regularly assessing the health status of both the dying patient and the patient's family members and detecting health problems early to prevent further damage.

Since most nurses do not have a clear understanding of death, it has been reported that they feel frustration, sadness, fear, and pressure when they have to care for dying patients [7-9]. Sasahara et al. [10] found that most nurses experienced difficulties in providing care for dying patients and did not have much knowledge about coping with death or dying. In contrast, nurses who have a positive attitude toward providing care for dying patients realize the meaning and value of life based on contemplating death while going through the death of patients, accept themselves and others for who they are, empathize with the patient's pain, and provide a higher quality of nursing care $[3,8]$.

Involvement is defined as a broad emotional relationship between participants and nurses, including the establishment of rapport [11]. Involvement in dying patients and family care refers to the practical psychological experience from nurses establishing a relationship with dying patients and their family members while providing care for them [4]. The Nurses' Involvement in Patients' Dying and Death Scale (NIPDYDS) is a validated tool developed after collecting qualitative data among nurses in Japan in order to measure involvement with dying patients and family care [4]. This tool consists of four sub-factors ("uncertainty and difficulty dealing with death and dying", "deep involvement in death and dying patients", "capacity-building to handle death and dying", and "getting used to death and dying") and 40 items. The strength of the NIPDYDS is that it is not limited to one-dimensional responses to caring for dying patients such as attitude, burnout, sadness, and loss; instead, it measures the deep internal responses experienced by nurses while providing care for dying patients and their family members.

Some studies in South Korea have investigated factors that influenced nurses' performance of care for dying patients $[3,12]$, the association between stress from caring for dying patients and the performance of care for dying patients [5,7,9], the relationships between nurses' attitudes toward death and nursing for end-of-life patients [8], and the association between nurses' attitudes toward caring for dying patients and capacity for empathy [2]. As demonstrated, in the field of nursing care for dying patients in South Korea, most research has dealt with nurses' simple responses to caring for dying patients and their family members, as Kondo and Nagata [4] pointed out. It is thus necessary to pay attention to nurses' involvement with dying patients and family care. However, no tools in South Korea are available to measure involvement in care.

This study conducted a validation study of the NIPDYDS [4], which was developed in Japan, to determine whether it is applicable in the South Korean context. Therefore, the aim of this study was to translate the NIPDYDS [4] into Korean, thereby creating a measurement tool entitled the Nurses' Involvement in Dying Patients and Family Care (NIDPFC), which is suitable for South Korean culture and sensibilities, and to examine the validity and reliability of the NIDPFC.

\section{METHODS}

\section{Study design}

This methodological study aimed to measure the validity and reliability of the NIDPFC measurement tool. After receiving permission from the author of the original tool, it was validated according to the tool development procedure outlined by DeVellis [13].

\section{Process of item development}

\section{1) Preparation of preliminary items}

To prepare the preliminary items for the NIDPFC, the NIPDYDS [4] was translated according to the World Health Organization [14] guideline. First, the 40 items in the NIPDYDS [4] were translated considering the context of nursing in South Korea in order to preserve the meaning. The items translated to Korean were sent to a nurse who is fluent in both Korean and English and worked at the Center for International $\mathrm{Co}^{-}$ operation at a university hospital for back-translation. The original items and back-translated items were reviewed for consistency, and no items were revised following the review. 


\section{2) First round of tests for content validity}

According to the suggestion made by Lynn [15] that an expert panel to test content validity should consist of at least three to 10 experts, this study recruited seven experts: two professors of nursing with certification in gerontological nursing, one hospice nurse specialist, one nursing $\mathrm{PhD}$ graduate, and three nurses with more than 10 years of experience providing care for dying patients. Content validity was measured as "not relevant" (1 point), "limited relevance and needs revision" (2 points), "relevant but needs some revision" (3 points), and "very relevant" (4 points). Opinions on each item were collected. The item-content validity index (I-CVI) of each item was calculated using the proportion of experts who gave the item either 3 or 4 points [15], and the resulting I-CVI values ranged from 0.43 to 1.00 . The CVI of the tool was checked using the scale-content validity index/average (S-CVI/AVE), which calculates the average of I-CVI, and the scale-content validity index/universal agreement (S-CVI/UA), which calculates the proportion of items with an I-CVI of 1.0 [16]. The S-CVI/AVE was 0.86 , and the S-CVI/UA was 0.40 . In the first round of expert content validity testing, 12 items had an I-CVI lower than 0.80 . The authors reviewed the meaning of these 12 items and the suggestions for revision from experts, deleted four items, and created 36 preliminary items. The ICVI of the preliminary items ranged from 0.71 to 1.00 .

\section{3) Review of item comprehensibility and Korean language quality}

Three elementary school students (two in the fourth grade and one in the sixth grade) and four nurses participated in testing the comprehensibility of the instrument, and one journalist and one writer reviewed the text for grammatical errors. Although in general there were no items that were hard to understand, according to the opinions expressed in the Korean language review, the expressions in three items were revised. Specifically, the revisions were from "I feel like I am not being helpful when I watch patients die although I made a lot of effort" to "I feel like I am not being helpful when I watch patients die despite my efforts", from "my way of thinking changed as I cared for dying patients" to "I think my way of thinking changed as I cared for dying patients", and from "although I am interested in patients who are dying and their family members, I maintain an adequate distance" to "although I am interested in patients who are dying and their family members, I maintain a therapeutic relationship".

\section{4) Second round of testing for content validity}

In order to test the content validity of the 36 revised preliminary items, seven experts who did not overlap with the experts from the first round (three professors of nursing, one nursing $\mathrm{PhD}$ student, one nurse with more than 20 years of nursing experience, and two nurses who worked for more than 10 years in a geriatric ward) evaluated item validity. The I-CVI of 36 items ranged from 0.86 to 1.00 , the S-CVI/AVE was 0.93 , and the S-CVI/UA was 0.54 . After reviewing the items based on CVI results and expert opinions regarding revisions, an item with an I-CVI of 0.71 was deleted, yielding 35 preliminary items.

\section{Study participants}

The participants of this study were nurses who provided care for dying patients and their family members in South Korea. The inclusion criteria were nurses who were working at hospitals at the level of convalescent hospitals or higher, who had experienced patient death in the past 5 years, and who understood the aims of the study and agreed to participate. Nurses working in outpatient, surgical, and recovery wards who did not perform nursing care for dying patients were excluded. This study included nurses working at one university hospital, three general hospitals, and a convalescent hospital in J Province.

The sample size required for this study was determined based on the sample sizes required for exploratory factor analysis (EFA) and confirmatory factor analysis (CFA), respectively. The sample size required for EFA was determined by referring to the standard that the sample size should be five to 10 times the number of items [17]. There were 35 preliminary items, requiring around 180 to 360 participants, so it was planned to recruit 200. According to the standard proposed by Myers et al. [18] that suggested a sample size of at least 200 for CFA, it was planned to recruit 200 subjects. Therefore, this study required a total of 400 participants, and considering a $10 \%$ dropout rate, 440 surveys were distributed. Among those, 415 were returned ( $94.3 \%$ response rate), and excluding five that 
were incomplete, a final sample of 410 surveys were analyzed.

\section{Research tools}

\section{1) Nurses' involvement in dying patients and family care}

The NIPDYDS developed by Kondo and Nagata [4] was revised to measure nurses' involvement in dying patients and family care. The NIPDYDS has four sub-factors and 40 items. After receiving approval to use the NIPDYDS, the 40 items were translated into Korean through a translation and backtranslation process, tested for content validity, and revised to 35 preliminary items. Each item was scored as follows: "always", 4 points; "mostly", 3 points; "rarely", 2 points; and "never", 1 point. A higher score suggested a higher level of nurse involvement. Cronbach's $\alpha$ for the original scale was 0.71 [4], and Cronbach's $\alpha$ for the 35 preliminary items in this study was 0.83 .

\section{2) Attitude toward nursing care for the dying}

In order to determine criterion validity, the Frommelt Attitudes toward Nursing Care of the Dying Scale, developed by Frommelt [19] and translated and revised and updated by Cho and Kim [20], was used to measure attitudes toward nursing care of the dying. This tool is composed of 30 items (15 positively worded items and 15 negatively worded items), and is measured using a 4-point Likert scale from "always" (4 points), "mostly" (3 points), and "rarely" (2 points) to "never" (1 point). The range of possible scores is from 30 to 120 , and a higher score indicates a more positive attitude toward nursing care for the dying. Cronbach's $\alpha$ as reported by Cho and Kim [20] was 0.86 , and Cronbach's $\alpha$ in this study was 0.76 .

\section{Data collection}

In order to protect study participants, this study received approval from the W University Institutional Review Board (NO. WKIRB-202006-SB-022). Data collection took place from June 23 to July 17, 2020. The study aims and procedures were explained to the directors of one university hospital, three general hospitals, and a convalescent hospital in J province. After receiving their approval, the first author delivered the structured surveys and retrieved them in person. Throughout the data collection process, the study aims and purpose, the voluntary nature of participation, the possibility of discon- tinuing participation, and personal data privacy were verbally explained to participants. A consent form was then provided, and written consent was obtained. It required around $10 \mathrm{~min}-$ utes to complete the survey, and after survey completion, a small gift was provided as a token of appreciation.

\section{Data analysis}

The data collected in this study were analyzed as follows using SPSS for Windows version 24.0 and AMOS version 24.0.

1) The general characteristics of participants were analyzed in terms of frequency, percentile, mean, and standard deviation.

2) Items were analyzed using the item-total correlation (ITC). 3) The Kaiser-Meyer-Olkin (KMO) test and Bartlett's test of sphericity were used to determine the sampling adequacy. Principal component analysis (PCA) with varimax rotation was used for analysis.

4) In CFA, the model fit was analyzed using the goodness of fit index (GFI), the adjusted goodness of fit index (AGFI), the comparative fit index (CFI), the normed fit index (NFI), the Tucker-Lewis Index (TLI), and the root mean squared error of approximation (RMSEA). Convergent validity was tested using average variance extracted (AVE), and construct reliability (CR), and divergent validity was tested using AVE and the square of the Pearson correlation coefficient.

5) Criterion validity was analyzed using Pearson correlation coefficients.

6) In order to test reliability that indicates internal consistency of the tool, Cronbach's $\alpha$ coefficient was calculated.

\section{RESULTS}

\section{General characteristics of participants}

The average age of the participants in this study was 33.22 \pm 9.43 years, and $95.6 \%$ of the participants were women. Over half $(59.5 \%)$ of the participants were unmarried, and $66.6 \%$ responded that they were not religious. The majority (76.4\%) of participants had completed a bachelor's degree, and $84.4 \%$ of the participants were general nurses. Their average length of clinical experience was $9.14 \pm 8.79$ years, and $87.8 \%$ of the nurses had worked in their current position for 5 years or less. The majority (54.4\%) of the participants worked in internal 
medicine wards, followed by $31.5 \%$ in surgical wards, and $14.1 \%$ in others. Furthermore, $32.4 \%$ of the participants had cared for dying patients 5 times or less, and $56.8 \%$ had experienced the death of someone close. Over half of the participants (57.8\%) reported that they had not received any education related to nursing care for dying patients (Table 1).

\section{First round of item analysis}

The results from the first round of item analysis of the 35 items showed that the ITC ranged from 0.00 to 0.47 . There were 16 items with correlation coefficients below 0.30 , but af- ter carefully reviewing the item content and meaning, only one item ("I find it difficult because I do not know how to care for dying patients".) was deleted. Therefore, as a result of the item analysis, 34 items were selected.

\section{Analysis of construct validity}

\section{1) Exploratory factor analysis}

Data from 210 participants were used to perform EFA. The first factor analysis showed that the KMO value was 0.81 and Bartlett's test of sphericity yielded a result of $\chi^{2}=2925.51$ $(d f=561, P<0.001)$. Therefore, it was confirmed that the sam-

Table 1. General Characteristics of the Participants ( $N=410)$.

\begin{tabular}{|c|c|c|c|c|}
\hline \multirow[t]{2}{*}{ Characteristics } & \multirow{2}{*}{ Categories } & $\begin{array}{c}\text { Total } \\
(n=410)\end{array}$ & \multirow{2}{*}{$\begin{array}{c}\begin{array}{c}\text { Exploratory factor } \\
\text { analysis }(\mathrm{n}=210)\end{array} \\
\text { Mean } \pm \text { SD/n (\%) }\end{array}$} & \multirow{2}{*}{$\begin{array}{c}\text { Confirmatory facto } \\
\text { analysis }(n=200)\end{array}$} \\
\hline & & Mean $\pm S D / n(\%)$ & & \\
\hline Age (yr) & & $33.22 \pm 9.43$ & $32.72 \pm 9.68$ & $33.75 \pm 9.14$ \\
\hline \multirow[t]{2}{*}{ Sex } & Male & $18(4.4)$ & $4(1.9)$ & $14(7.0)$ \\
\hline & Female & $392(95.6)$ & $206(98.1)$ & $186(93.0)$ \\
\hline \multirow[t]{2}{*}{ Marital status } & Unmarried & $244(59.5)$ & $130(61.9)$ & $114(57.0)$ \\
\hline & Married & $166(40.5)$ & $80(38.1)$ & $86(43.0)$ \\
\hline \multirow[t]{2}{*}{ Religious } & Yes & $137(33.4)$ & $66(31.4)$ & $71(35.5)$ \\
\hline & No & $273(66.6)$ & $144(68.6)$ & $129(64.5)$ \\
\hline \multirow[t]{3}{*}{ Education level } & Community college & $74(18.0)$ & $31(14.8)$ & $43(21.5)$ \\
\hline & Undergraduate & $313(76.4)$ & $167(79.5)$ & $146(73.0)$ \\
\hline & Graduate & $23(5.6)$ & $12(5.7)$ & $11(5.5)$ \\
\hline \multirow[t]{3}{*}{ Position } & Staff & $346(84.4)$ & $183(87.1)$ & $163(81.5)$ \\
\hline & Charge nurse & $39(9.5)$ & $18(8.6)$ & $21(10.5)$ \\
\hline & Head nurse & $25(6.1)$ & $9(4.3)$ & $16(8.0)$ \\
\hline \multirow[t]{2}{*}{ Clinical career (yr) } & & $9.14 \pm 8.79$ & $9.74 \pm 9.60$ & $8.51 \pm 7.75$ \\
\hline & & $2.69 \pm 2.53$ & $2.50 \pm 2.30$ & $2.89 \pm 2.75$ \\
\hline \multirow[t]{3}{*}{ Present department career (yr) } & $\leq 5$ & $360(87.8)$ & $180(88.1)$ & $175(87.5)$ \\
\hline & $6 \sim 10$ & $43(10.5)$ & $23(10.9)$ & $20(10.0)$ \\
\hline & $11 \sim 15$ & $7(1.7)$ & $2(1.0)$ & $5(2.5)$ \\
\hline \multirow[t]{3}{*}{ Hospital type } & University hospital & $221(53.9)$ & $204(97.1)$ & $17(8.5)$ \\
\hline & General hospital & $179(43.7)$ & $6(2.9)$ & $173(86.5)$ \\
\hline & Nursing hospital & $10(2.4)$ & 0 & $10(5.0)$ \\
\hline \multirow[t]{3}{*}{ Working unit } & Internal medicine ward & $223(54.4)$ & $160(76.2)$ & $63(31.5)$ \\
\hline & Surgical ward & $129(31.5)$ & $27(12.8)$ & $102(41.0)$ \\
\hline & Others & $58(14.1)$ & $23(11.0)$ & $35(17.5)$ \\
\hline \multirow[t]{4}{*}{ Experience of caring for dying patients } & 5 times or fewer & $133(32.4)$ & $45(21.4)$ & $88(44.0)$ \\
\hline & 5 to 10 times & $85(20.7)$ & $48(22.9)$ & $37(18.5)$ \\
\hline & 11 to 30 times & $72(17.6)$ & $37(17.6)$ & $35(17.5)$ \\
\hline & More than 30 times & $120(29.3)$ & $80(38.1)$ & $40(20.0)$ \\
\hline \multirow{2}{*}{$\begin{array}{l}\text { Experience of the death of a } \\
\text { close person }\end{array}$} & Yes & $233(56.8)$ & $130(61.9)$ & $103(51.5)$ \\
\hline & No & $177(43.2)$ & $80(38.1)$ & $97(48.5)$ \\
\hline \multirow[t]{2}{*}{ Attendance at hospice care education } & Yes & $173(42.2)$ & $95(45.2)$ & $78(39.0)$ \\
\hline & No & 237 (57.8) & $115(54.8)$ & $122(61.0)$ \\
\hline
\end{tabular}


ple size and number of items were adequate for factor analysis. The number of factors with an eigenvalue greater than 1.0 was 8 , and the cumulative total variance was $60.88 \%$. Communality was 0.47 to 0.77 , and since items are regarded to have high discrimination and to be of high quality with values greater than 0.40 [21], no items were deleted. Factor loading ranged from 0.40 to 0.82 , which exceeded the lower limit of factor loading of 0.30 [22]; therefore, no items needed to be re- moved. However, the eighth factor was composed of one item. Thus, the number of items was established, and additional factor analysis was conducted.

The second round of factor analysis was conducted without deleting any items, and with the designation of four factors based on the composite factors of the NIPDYDS. The KMO value was 0.81, and Bartlett's test of sphericity yielded a result of $\chi^{2}=2925.51(\mathrm{df}=561, \mathrm{P}<0.001)$. The cumulative total

Table 2. Exploratory Factor Analysis ( $N=210)$

\begin{tabular}{|c|c|c|c|c|c|c|}
\hline Factor (items) & $\begin{array}{l}\text { Item } \\
\text { No. }\end{array}$ & Item & 1 & 2 & 3 & 4 \\
\hline \multirow[t]{7}{*}{ Burden (7) } & 1. & $\begin{array}{l}\text { Caring for dying patients makes me feel torn: sometimes I want to quit my job } \\
\text { and sometimes I want keep working }\end{array}$ & 0.73 & & & \\
\hline & 2. & $\begin{array}{l}\text { I am not confident about caring for dying patients and their families. I think that I } \\
\text { am not suited to be a nurse }\end{array}$ & 0.72 & & & \\
\hline & 3. & $\begin{array}{l}\text { A patient dies in a bed one day and is replaced by another the next day. Every day } \\
\text { starts as if nothing happened. This makes me uncomfortable }\end{array}$ & 0.71 & & & \\
\hline & 4. & $\begin{array}{l}\text { I am devoting myself to a new patient to forget my sorrow over the death of a } \\
\text { previous patient }\end{array}$ & 0.68 & & & \\
\hline & 5. & I feel anxious about doing well in a place where patients die almost every day & 0.67 & & & \\
\hline & 6. & Being involved in caring for dying patients pushes me to the limit & 0.64 & & & \\
\hline & 7. & I feel nothing helps me when I see many patients die despite all my efforts & 0.61 & & & \\
\hline \multirow[t]{8}{*}{ Deep involvement (8) } & 8. & I know how to care for dying patients, including steering conversations & & 0.76 & & \\
\hline & 9. & I am confident in my ability to care for dying patients and their families & & 0.75 & & \\
\hline & 10. & $\begin{array}{l}\text { I have learned to empathize with patients' spiritual distress and emotional } \\
\text { suffering and try to do what I can to ease their pain }\end{array}$ & & 0.72 & & \\
\hline & 11. & I make efforts to touch dying patients to understand their suffering & & 0.65 & & \\
\hline & 12. & I understand the sorrow and suffering of dying patients and their families & & 0.64 & & \\
\hline & 13. & I think hard about how to help dying patients and their families & & 0.57 & & \\
\hline & 14. & $\begin{array}{l}\text { Despite painful experiences, I like to be with, and helpful to, a patient and his or } \\
\text { her family }\end{array}$ & & 0.57 & & \\
\hline & 15. & I am able to maintain an adequate distance from patients & & 0.52 & & \\
\hline \multirow[t]{5}{*}{ Resilience (5) } & 16. & I feel nothing when a patient is dead. My job is to carry on with regular duties & & & 0.84 & \\
\hline & 17. & I am accustomed to death & & & 0.75 & \\
\hline & 18. & $\begin{array}{l}\text { When caring for a patient on his or her deathbed, I deal with him or her in the } \\
\text { standard and routine way without feeling anything }\end{array}$ & & & 0.72 & \\
\hline & 19. & I have no difficulty eating, even after I have just finished postmortem care & & & 0.66 & \\
\hline & 20. & I feel relieved when a patient I had difficulties caring for dies & & & 0.65 & \\
\hline \multirow[t]{4}{*}{ Empathy (4) } & 21. & $\begin{array}{l}\text { I feel sad about the death of a patient whom I have been caring for since the onset } \\
\text { of their illness }\end{array}$ & & & & 0.82 \\
\hline & 22. & $\begin{array}{l}\text { I feel that I could have done much more for a deceased patient I was attached to, } \\
\text { and regret that I did not }\end{array}$ & & & & 0.81 \\
\hline & 23. & Caring for dying patients makes me feel bitter and hurt & & & & 0.57 \\
\hline & 24. & $\begin{array}{l}\text { I feel that I could have done much more for a deceased patient I was attached to, } \\
\text { and regret that I did not }\end{array}$ & & & & 0.55 \\
\hline Initial eigenvalue & & & 3.61 & 3.56 & 3.17 & 2.91 \\
\hline Explained variance (\%) & & & 15.0 & 14.8 & 13.2 & 12.1 \\
\hline Cumulative variance (\%) & & & 15.0 & 29.9 & 43.1 & 55.2 \\
\hline
\end{tabular}


variance of the four factors was $50.77 \%$, the communality of the 34 items ranged from 0.18 to 0.72 , and the factor loadings ranged from 0.33 to 0.84 . The item with a communality lower than 0.40 and the items with an ITC lower than 0.30 in the first factor analysis were deleted, and factor analysis was conducted again.

The third round of factor analysis was conducted with 32 items and four factors. The KMO value was 0.81, and Bartlett's test of sphericity yielded a value of $\chi^{2}=2732.15(\mathrm{df}=496, \mathrm{P}<0.001)$.
The cumulative total variance was $47.86 \%$, communality ranged from 0.28 to 0.72 , and factor loadings ranged from 0.28 to 0.84 . The items with a communality lower than 0.40 and the six items that had an ITC lower than 0.30 in the first factor analysis were deleted, and factor analysis was conducted again.

The fourth round of factor analysis was conducted with 26 items and four factors. The KMO value was 0.81 , and Bartlett' $\mathrm{s}$ test of sphericity yielded a result of $\chi^{2}=2257.09(\mathrm{df}=325, \mathrm{P}<$

Table 3. Convergent Validity ( $\mathrm{N}=200)$.

\begin{tabular}{|c|c|c|c|c|c|c|}
\hline Factor & $\begin{array}{l}\text { Item } \\
\text { No. }\end{array}$ & Item & $\begin{array}{l}\text { Factor } \\
\text { loading }\end{array}$ & Error & AVE & CR \\
\hline \multirow[t]{7}{*}{ Burden } & 1. & $\begin{array}{l}\text { Caring for dying patients makes me feel torn: sometimes I want to quit my } \\
\text { job and sometimes I want keep working }\end{array}$ & 0.71 & 0.26 & 0.64 & 0.93 \\
\hline & 2. & $\begin{array}{l}\text { I am not confident about caring for dying patients and their families. I think } \\
\text { that I am not suited to be a nurse }\end{array}$ & 0.71 & 0.23 & & \\
\hline & 3. & $\begin{array}{l}\text { A patient dies in a bed one day and is replaced by another the next day. } \\
\text { Every day starts as if nothing happened. This makes me uncomfortable }\end{array}$ & 0.75 & 0.22 & & \\
\hline & 4. & $\begin{array}{l}\text { I am devoting myself to a new patient to forget my sorrow over the death } \\
\text { of a previous patient }\end{array}$ & 0.66 & 0.29 & & \\
\hline & 5. & $\begin{array}{l}\text { I feel anxious about doing well in a place where patients die almost every } \\
\text { day }\end{array}$ & 0.64 & 0.30 & & \\
\hline & 6. & Being involved in caring for dying patients pushes me to the limit & 0.69 & 0.27 & & \\
\hline & 7. & I feel nothing helps me when I see many patients die despite all my efforts & 0.70 & 0.31 & & \\
\hline \multirow[t]{8}{*}{ Deep involvement } & 8. & I know how to care for dying patients, including steering conversations & 0.62 & 0.29 & 0.62 & 0.92 \\
\hline & 9. & I am confident in my ability to care for dying patients and their families & 0.58 & 0.36 & & \\
\hline & 10. & $\begin{array}{l}\text { I have learned to empathize with patients' spiritual distress and emotional } \\
\text { suffering and try to do what I can to ease their pain }\end{array}$ & 0.76 & 0.19 & & \\
\hline & 11. & I make efforts to touch dying patients to understand their suffering & 0.74 & 0.21 & & \\
\hline & 12. & I understand the sorrow and suffering of dying patients and their families & 0.72 & 0.23 & & \\
\hline & 13. & I think hard about how to help dying patients and their families & 0.66 & 0.24 & & \\
\hline & 14. & $\begin{array}{l}\text { Despite painful experiences, l like to be with, and helpful to, a patient and } \\
\text { his or her family }\end{array}$ & 0.71 & 0.27 & & \\
\hline & 15. & I am able to maintain an adequate distance from patients & 0.42 & 0.39 & & \\
\hline \multirow[t]{5}{*}{ Resilience } & 16. & $\begin{array}{l}\text { I feel nothing when a patient is dead. My job is to carry on with regular } \\
\text { duties }\end{array}$ & 0.85 & 0.15 & 0.56 & 0.86 \\
\hline & 17. & Iam accustomed to death & 0.61 & 0.45 & & \\
\hline & 18. & $\begin{array}{l}\text { When caring for a patient on his or her deathbed, I deal with him or her in } \\
\text { the standard and routine way without feeling anything }\end{array}$ & 0.70 & 0.25 & & \\
\hline & 19. & I have no difficulty eating, even after I have just finished postmortem care & 0.61 & 0.45 & & \\
\hline & 20. & I feel relieved when a patient I had difficulties caring for dies & 0.48 & 0.41 & & \\
\hline \multirow[t]{4}{*}{ Empathy } & 21. & $\begin{array}{l}\text { I feel sad about the death of a patient whom I have been caring for since } \\
\text { the onset of their illness }\end{array}$ & 0.88 & 0.13 & 0.67 & 0.89 \\
\hline & 22. & $\begin{array}{l}\text { I feel that I could have done much more for a deceased patient I was } \\
\text { attached to, and regret that I did not }\end{array}$ & 0.86 & 0.16 & & \\
\hline & 23. & Caring for dying patients makes me feel bitter and hurt & 0.61 & 0.35 & & \\
\hline & 24. & $\begin{array}{l}\text { I feel that I could have done much more for a deceased patient I was } \\
\text { attached to, and regret that I did not }\end{array}$ & 0.48 & 0.40 & & \\
\hline
\end{tabular}

AVE: average variance extracted, CR : critical ratio. 
Table 4. Discriminant Validity (N=200).

\begin{tabular}{|c|c|c|c|}
\hline & Burden & $\begin{array}{c}\text { Deep } \\
\text { involvement }\end{array}$ & Resilience \\
\hline & $r^{2}$ & $r^{2}$ & $r^{2}$ \\
\hline Deep involvement & 0.01 & & \\
\hline Resilience & -0.01 & 0.00 & \\
\hline Empathy & 0.22 & 0.15 & -0.04 \\
\hline
\end{tabular}

0.001). The cumulative total variance was $53.41 \%$, communality ranged from 0.35 to 0.73 , and factor loadings ranged from 0.40 to 0.84 . One item with a communality lower than 0.40 and two items with an ITC lower than 0.30 in the first factor analysis were deleted, and factor analysis was repeated. The fifth round of factor analysis was conducted with 24 items and four factors. The KMO value was 0.80, Bartlett's test

Table 5. Item Analysis ( $\mathrm{N}=410)$.

\begin{tabular}{|c|c|c|c|c|c|}
\hline Factor & $\begin{array}{l}\text { Item } \\
\text { No. }\end{array}$ & Item & Mean \pm SD & $\begin{array}{l}\text { Corrected } \\
\text { item-total } \\
\text { correlation }\end{array}$ & $\begin{array}{l}\text { Alpha if } \\
\text { item deleted }\end{array}$ \\
\hline \multirow[t]{7}{*}{ Burden } & 1. & $\begin{array}{l}\text { Caring for dying patients makes me feel torn: sometimes I want to quit } \\
\text { my job and sometimes I want keep working }\end{array}$ & $1.61 \pm 0.72$ & 0.41 & 0.81 \\
\hline & 2. & $\begin{array}{l}\text { I am not confident about caring for dying patients and their families. I } \\
\text { think that I am not suited to be a nurse }\end{array}$ & $1.66 \pm 0.68$ & 0.37 & 0.81 \\
\hline & 3. & $\begin{array}{l}\text { A patient dies in a bed one day and is replaced by another the next day. } \\
\text { Every day starts as if nothing happened. This makes me uncomfortable }\end{array}$ & $1.96 \pm 0.71$ & 0.49 & 0.80 \\
\hline & 4. & $\begin{array}{l}\text { I am devoting myself to a new patient to forget my sorrow over the } \\
\text { death of a previous patient }\end{array}$ & $1.80 \pm 0.72$ & 0.41 & 0.81 \\
\hline & 5. & $\begin{array}{l}\text { I feel anxious about doing well in a place where patients die almost } \\
\text { every day }\end{array}$ & $2.04 \pm 0.71$ & 0.30 & 0.81 \\
\hline & 6. & Being involved in caring for dying patients pushes me to the limit & $2.11 \pm 0.68$ & 0.34 & 0.81 \\
\hline & 7. & $\begin{array}{l}\text { I feel nothing helps me when I see many patients die despite all my } \\
\text { efforts }\end{array}$ & $2.03 \pm 0.78$ & 0.49 & 0.80 \\
\hline \multirow[t]{8}{*}{ Deep involvement } & 8. & I know how to care for dying patients, including steering conversations & $2.05 \pm 0.74$ & 0.34 & 0.81 \\
\hline & 9. & I am confident in my ability to care for dying patients and their families & $2.19 \pm 0.69$ & 0.37 & 0.81 \\
\hline & 10. & $\begin{array}{l}\text { I have learned to empathize with patients' spiritual distress and } \\
\text { emotional suffering and try to do what I can to ease their pain }\end{array}$ & $2.50 \pm 0.66$ & 0.45 & 0.81 \\
\hline & 11. & I make efforts to touch dying patients to understand their suffering & $2.60 \pm 0.68$ & 0.49 & 0.80 \\
\hline & 12. & I understand the sorrow and suffering of dying patients and their families & $2.63 \pm 0.69$ & 0.44 & 0.81 \\
\hline & 13. & I think hard about how to help dying patients and their families & $2.38 \pm 0.65$ & 0.48 & 0.80 \\
\hline & 14. & $\begin{array}{l}\text { Despite painful experiences, I like to be with, and helpful to, a patient } \\
\text { and his or her family }\end{array}$ & $2.57 \pm 0.74$ & 0.44 & 0.81 \\
\hline & 15. & I am able to maintain an adequate distance from patients & $2.43 \pm 0.69$ & 0.25 & 0.81 \\
\hline \multirow[t]{5}{*}{ Resilience } & 16. & $\begin{array}{l}\text { I feel nothing when a patient is dead. My job is to carry on with } \\
\text { regular duties }\end{array}$ & $1.85 \pm 0.73$ & 0.11 & 0.82 \\
\hline & 17. & I am accustomed to death & $1.80 \pm 0.84$ & 0.20 & 0.82 \\
\hline & 18. & $\begin{array}{l}\text { When caring for a patient on his or her deathbed, I deal with him } \\
\text { or her in the standard and routine way without feeling anything }\end{array}$ & $1.89 \pm 0.71$ & 0.11 & 0.82 \\
\hline & 19. & $\begin{array}{l}\text { I have no difficulty eating, even after I have just finished postmortem } \\
\text { care }\end{array}$ & $2.42 \pm 0.84$ & 0.07 & 0.82 \\
\hline & 20. & I feel relieved when a patient I had difficulties caring for dies & $1.71 \pm 0.72$ & 0.28 & 0.81 \\
\hline \multirow[t]{4}{*}{ Empathy } & 21. & $\begin{array}{l}\text { I feel sad about the death of a patient whom I have been caring for } \\
\text { since the onset of their illness }\end{array}$ & $2.69 \pm 0.78$ & 0.44 & 0.80 \\
\hline & 22. & $\begin{array}{l}\text { I feel that I could have done much more for a deceased patient I was } \\
\text { attached to, and regret that I did not }\end{array}$ & $2.79 \pm 0.79$ & 0.47 & 0.80 \\
\hline & 23. & Caring for dying patients makes me feel bitter and hurt & $2.69 \pm 0.75$ & 0.41 & 0.81 \\
\hline & 24. & $\begin{array}{l}\text { I feel that I could have done much more for a deceased patient I was } \\
\text { attached to, and regret that I did not }\end{array}$ & $2.19 \pm 0.72$ & 0.48 & 0.80 \\
\hline
\end{tabular}


of sphericity yielded a result of $\chi^{2}=2030.60(\mathrm{df}=231, \mathrm{P}<0.001)$, communality ranged from 0.44 to 0.73 , and factor loadings ranged from 0.52 to 0.84 . The four factors explained $55.2 \%$ of the variation. The factor analysis was completed without any further removal of items (Table 2).

\section{2) Naming the factors}

The final results of the factor analysis derived 24 items across four factors. The first factor was named "burden" and included seven items. Its eigenvalue was 3.61, and the factor explained $15.0 \%$ of the variation. The second factor was named "deep involvement" and was composed of eight items. Its eigenvalue was 3.56, and the factor explained $14.8 \%$ of the variation. The third factor was named "resilience". This factor contained five items. Its eigenvalue was 3.17, and the factor explained $13.2 \%$ of the variation. The fourth factor, named "empathy", contained four items. Its eigenvalue was 2.91, and it explained $12.1 \%$ of the variation (Table 2).

\section{3) Confirmatory factor analysis}

CFA was conducted with the 24 items derived from the EFA and four factors. When the goodness of fit of the model was evaluated, $\chi^{2}$ was $993.58(\mathrm{df}=246, \mathrm{P}<0.001)$, GFI was 0.81 , AGFI was 0.77 , CFI was 0.82 , NFI was 0.78 , TLI was 0.80 , and RMSEA was 0.09 .

In order to confirm whether the factors explained the concept of involvement in a complementary manner, convergent validity was tested. The AVE was 0.64 for burden, 0.62 for deep involvement, 0.56 for resilience, and 0.67 for empathy. All factors had values greater than 0.50 . The CR was 0.93 for burden, 0.92 for deep involvement, 0.86 for resilience, and 0.89 for empathy, with all values greater than 0.70 (Table 3 ). In order to confirm that each factor measured unique characteristics, rather than measuring the same characteristic, discriminant validity was analyzed. The coefficient of determination $\left(\mathrm{r}^{2}\right)$ ranged from 0.04 to 0.22 , and all values were lower than the AVE of the four factors, which ranged from 0.56 to 0.67 (Table 4).

\section{Second round of item analysis}

After analyzing validity, in order to understand the homogeneity of the 24 items, a second round of item analysis was performed. As a result of the second item analysis, the ITC ranged from 0.07 to 0.49 . There were five items with values lower than 0.30 , but since they were not the majority of items [23], the 24 items of the NIDPFC were selected without further deletion of items (Table 5).

The mean and standard deviation values for the NIDPFC were as follows. The average score for all 24 items of the NIDPFC was $52.56 \pm 7.62$, and the averages for each factor were $13.21 \pm 3.72$ for burden, $19.33 \pm 3.92$ for deep involvement, $9.66 \pm 2.81$ of resilience, and $10.35 \pm 2.38$ for empathy.

Table 6. Criterion Validity ( $\mathrm{N}=410)$.

\begin{tabular}{|c|c|c|c|c|c|c|c|c|c|c|}
\hline & \multicolumn{10}{|c|}{ NIDPFC } \\
\hline & \multicolumn{2}{|c|}{ Total } & \multicolumn{2}{|c|}{ Burden } & \multicolumn{2}{|c|}{ Deep involvement } & \multicolumn{2}{|c|}{ Resilience } & \multicolumn{2}{|c|}{ Empathy } \\
\hline & $r$ & $P$ & $r$ & $P$ & r & $P$ & $r$ & $P$ & $r$ & $P$ \\
\hline FATCOD & 0.53 & $<0.001$ & 0.33 & $<0.001$ & 0.38 & $<0.001$ & 0.10 & 0.037 & 0.45 & $<0.001$ \\
\hline
\end{tabular}

NIDPFC: nurse's involvement in dying patients and family care, FATCOD: Frommelt attitudes toward nursing care of the dying scale.

Table 7. Reliability ( $\mathrm{N}=410)$.

\begin{tabular}{|c|c|c|c|c|c|c|}
\hline & \multicolumn{4}{|c|}{ NIPDFC } & \multicolumn{2}{|c|}{ Split-halves reliability } \\
\hline & Burden & Deep involvement & Resilience & Empathy & $1^{*}$ & $2^{\dagger}$ \\
\hline Cronbach's $\alpha$ & 0.86 & 0.86 & 0.78 & 0.79 & 0.86 & 0.78 \\
\hline
\end{tabular}

NIPDFC: nurse's involvement in dying patients and family care.

*First half of items (numbers 1 12), ${ }^{\dagger}$ Second half of items (numbers 13 24). 


\section{Criterion validity}

In this study, the NIDPFC and attitudes toward nursing care for dying patients had a correlation of $r=0.53(\mathrm{P}<0.001)$. Significant associations were found for each factor, with $r=0.65(P<0.001)$ for burden, $r=0.68(\mathrm{P}<0.001)$ for deep involvement, $r=0.34$ $(\mathrm{P}<0.001)$ for resilience, and $\mathrm{r}=0.67(\mathrm{P}<0.001)$ for empathy (Table 6).

\section{Analysis of reliability}

Cronbach's $\alpha$ for the 24 NIDPFC items was 0.82 . The value was 0.86 for burden, 0.86 for deep involvement, 0.78 for resilience, and 0.79 for empathy. The result of split-half reliability testing with the items divided by item order suggested that the value was 0.86 for the first half of items ( 1 to 12 ) and 0.78 for the second half of items (13 to 24) (Table 7).

\section{DISCUSSION}

This study was conducted to test the validity and reliability of the NIDPFC, a revised Korean version of the NIPDYDS developed by Kondo and Nagata [4], and to investigate the applicability of the tool. The Korean NIDPFC had 24 items measured with response options of "always" (4 points), "mostly" (3 points), "rarely" (2 points), and "never" (1 point). Higher scores suggest a higher involvement of nurses in care for dying patients and their family members.

The first factor of the NIDPFC derived in this study is burden. The items included in the first factor are those included in the "uncertainty and difficulty dealing with death and dying" factor in the original NIPDYDS tool [4]. In the NIPDYDS [4], 14 items composed this factor, but in this study, in the process of validating it in Korean, four items were removed, and three items were moved to the fourth factor, resulting in seven items. The content of the seven items in the first factor included sadness experienced by nurses while providing care for dying patients and their family members, as well as their subjective limits and conflicts, which is why the factor was named "burden". The stress associated with nursing care for dying patients causes a passive and diminished attitude, which has been reported to have a negative influence on the delivery of nursing care for dying patients, as it leads nurses to avoid active involvement $[7,8]$.

When nurses have to provide care for dying patients and their despairing family members, nurses experience a different type of stress from when they provide care for general patients due to their perceived helplessness (i.e., the sense that they cannot do anything to save the patients), their dedication that receives no compensation when the patient dies, and their psychological pain (e.g., despair) [9]. Frequent experiences of caring for dying patients can cause burnout or stress, and can feel burdensome even to professional medical staff. This study acknowledges this burden as a psychological response that nurses who care for dying patients can have and reflects it in the NIDPFC. Burden is an important factor derived in this study that should be differentiated from existing attitudes toward and ability to provide nursing care for dying patients.

The second factor of the NIDPFC is deep involvement. The items included in deep involvement are a combination of items from two factors ("deep involvement in death and dying patients" and "capacity-building to handle death and dying") in the original NIPDYDS [4]. In this study, this factor is composed of eight items about practical involvement in the care for dying patients and their family members. Perceptions of death are complex concepts that encompass an individual's feelings, perceptions, and personal beliefs about death and differ for each individual according to his or her values and experiences [5]. When delivering care for dying patients, nurses are in the position to clarify the goals of treatment, to help patients clearly recognize the situation, and to assist patients in understanding their own preferences and hopes [12]. Since nurses can sometimes try to avoid nursing care for dying patients and their family members as their pain and demands increase [24], in order to provide better care for participants, nurses need to deliver adequate care without wavering in the situation where life and death meet. Therefore, the level of nurses' involvement when caring for dying patients and their family members is an important factor to measure in order to provide high-quality nursing care for dying patients.

The third factor of the NIDPFC is resilience. After two of the seven items included in the "getting used to death and dying" factor in the original NIPDYDS [4] were removed, the remaining factors were included in the resilience factor. In the NIDPFC, the content regarded nurses experiencing death many 
times, overcoming their vague fears, getting used to caring for dying patients, and performing their duties resolutely, which led to the factor being named more positively, as "resilience", than the factor name used in the original scale. Resilience is defined as the ability to recover or easily adapt to change or misfortune [25]. Resilience also refers to a series of dynamic processes through which an individual can diminish negative outcomes and transform them into mature experiences in stress or crisis situations by actively using their available internal and external resources [26]. Resilience therefore can be defined as the ability to recover and get back up again despite difficulties or changes. Since more resilient nurses provide higher-quality care for dying patients and their family members, nurses' resilience is an important component of nursing care for dying patients and their family members [5]. Therefore, it is meaningful that resilience was derived as a factor of the NIDPFC in this study.

The last factor of the NIDPFC is empathy. The items included in two factors of the original NIPDYDS ("uncertainty and difficulty dealing with death and dying" and "deep involvement in death and dying patients") [4] were included in the empathy factor in this study. The fourth factor of the NIDPFC is composed of four items dealing with understanding and empathizing with the difficulties and grief of dying patients and their family members. Empathy is a very important concept in nursing that refers to deliberate efforts made to listen to $\mathrm{pa}^{-}$ tients, to envision their perspective, and to help them. Nurses who provide care to dying patients and their family members need to have empathy in order to provide adequate care [27]. According to many prior studies, higher levels of empathy among nurses were found to lead to an ability to deliver higher-quality nursing care $[5,28]$. Nurses who provide care to dying patients at the end of their life and their family members, based on empathy toward patients, establish meaningful trust through effective communication and by responding sensitively to the needs of patients and family members [5,29]. For nurses, empathy is an essential virtue that not only reduces the difficulty faced by patients and their family members and helps them heal, but also enhances nurses' self-understanding and improves their self-efficacy by helping them to expect positive effects from their work [30]. Therefore, it is meaningful that empathy, which did not exist in the original NIPDYDS [4], was derived as the last factor in this study that validated the original scale in Korean.

To validate the NIPDYDS in Korean, this study aimed to test the NIDPFC in a logical and systematic manner by following the tool development guideline developed by DeVellis [13]. Considering the context in which care for dying patients and family members is delivered in South Korea, a significant aspect of this study is that it included institutions such as university hospitals, general hospitals, and convalescent hospitals beyond the hospice ward. However, the study was only conducted in J province. Thus, there is a limitation to the generalizability of this study. Future research among nurses in other regions is warranted.

The NIDPFC, which was validated in this study, has validity and reliability, so we recommend the following. First, the NIDPFC should be used in various studies exploring the concept of involvement in care. Second, since this study only considered nurses in J province, repeated validation should be conducted in samples of people with other occupations and participants from various regions.

\section{CONFLICT OF INTEREST}

No potential conflict of interest relevant to this article was reported.

\section{ORCID}

Mi Yeon Kim, https://orcid.org/0000-0001-8330-5990

Hanna Lee, https://orcid.org/0000-0001-6084-262X

Inyoung Lee, https://orcid.org/0000-0002-2814-9531

Mirim Lee, https://orcid.org/0000-0003-2237-7899

Haeryun Cho, https://orcid.org/0000-0001-7366-9774

\section{AUTHOR'S CONTRIBUTIONS}

Conceptualization: MYK, HL, IL, ML, HC. Data curation: MYK, HL, IL, ML. Formal analysis: MYL, HL, IL, ML, HC. Funding acquisition: MYL, HL, IL, ML, HC. Investigation: MYK, HL, IL, ML. Methodology: HC. Project administration: HC. Resources: MYK, HL, IL, ML. Software: MYK, HL, IL. Supervision: HC. Validation: MYK, HL, IL. Visual- 
ization: MYK, HL, IL. Writing - original draft: MYK, HL, IL. Writing - review \& editing: MYK, HL, HC.

\section{SUPPLEMENTARY MATERIALS}

Supplementary materials can be found via https://doi. org/10.14475/kjhpc.2020.23.4.228.

\section{REFERENCES}

1. Statistics Korea [Internet]. 2018 Population trends survey: Provisional results of birth and death statistics. Daejeon: Statistics Korea; 2019 [cited 2020 Mar 24]. Available from: http://kostat.go.kr/portal/korea/kor_nw/1/2/3/index.board.

2. Kim EH, Lim YM. The mediating effect of compassionate competence on the relationship between nurses' spirituality and attitude toward care of dying patients. J East-West Nurs Res 2019;25:167-74.

3. Noh SS, Lee CK, Sung YH. Predictors of terminal care performance of clinical nurses for cancer patients. J Korean Critical Care Nur 2016;9:6170.

4. Kondo M, Nagata H. Nurses' involvement in patients' dying and death: Scale development and validation. Omega (Westport) 2015;70:278 300.

5. Kim HY, Nam KH, Kwon SH. Mediating effects of empathy and resilience on the relationship between terminal care stress and performance for nurses in a tertiary hospital. Korean J Hosp Palliat Care 2017;20:253-63.

6. Choi ES, Kim KS. Experiences of family caregivers of patients with terminal cancer. J Korean Acad Nurs 2012;42:280-90.

7. Baek EK, Choi EJ. Terminal care stress, job satisfaction and terminal care performance for nurses in internal medicine wards. Korean J Hosp Palliat Care 2015;18:267-75.

8. Seo MJ, Kim JY, Kim SH, Lee TW. Nurses attitudes toward death, coping with death and understanding and performance regarding EOL care: Focus in nurses at ED, ICU and oncology department. Korean J Hosp Palliat Care 2013;16:108-17.

9. Woo YW, Kim KH, Kim KS. Death anxiety and terminal care stress among nurses and the relationship to terminal care performance. Korean J Hosp Palliat Care 2013;16:33-41.

10. Sasahara T, Miyashita M, Kawa M, Kazuma K. Difficulties encountered by nurses in the care of terminally ill cancer patients in general hospitals in Japan. Palliat Med 2003;17:520-6.

11. Kim CK, Lee SY, Lee YJ, Jeong JJ, Choe YY. Counseling dictionary. Seoul:Hakjisa corp.;2016.

12. Kim SK, Kim SH, Yun HY. Factors that influence end-of-life care provided by nurses in general hospitals. Korean J Medical Ethics 2019;22:53-72.

13. DeVellis RF. Scale development: theory and applications. 4th ed. Los Angeles:Sage publications;2016.

14. World Health Organization [Internet]. Process of translation and adaptation of instruments. Geneva: World Health Organization; c2020 [cited 2020 Mar 31]. Available from: https://www.who.int/substance_abuse/research_tools/translation/en/.

15. Lynn MR. Determination and quantification of content validity. Nurs Res 1986;35:382-5.

16. Polit DF, Beck CT. The content validity index: are you sure you know what's being reported? Critique and recommendations. Res Nurs Health 2006;29:489-97.

17. Costello AB, Osborne JW. Best practices in exploratory factor analysis: Four recommendations for getting the most from your analysis. Pract Assess Res Eval 2005;10:1-9.

18. Myers ND, Ahn S, Jin Y. Sample size and power estimates for a confirmatory factor analytic model in exercise and sport: a Monte Carlo approach. Res Q Exerc Sport 2011;82:412-23.

19. Frommelt KH. The effects of death education on nurses' attitudes toward caring for terminally ill persons and their families. Am J Hosp Palliat Care 1991;8:37-43.

20. Cho HJ, Kim ES. The effect of the death education program in the death anxiety and attitudes toward nursing care of the dying patients of nursing student. Korean J Hosp Palliat Care 2005;8:163-72.

21. Seong TJ. Theory and practice of questionnaire construction and analysis. 2nd ed. Seoul:Hskjisa corp.;2010.

22. Tabachnick BG, Fidell LS. Using multivariate statistics. 6th ed. Boston, Mass.; London: Pearson;c2013.

23. Lee HY, Noh SC. Advanced statistical analysis: theory and practice. Goyang:MoonWooSa;2017. p. 674-92.

24. Baldacchino DR. Nursing competencies for spiritual care. J Clin Nurs 2006;15:885-96.

25. Merriam-Webster, Inc. Webster's dictionary of the English language. 4th ed. Springfield, Mass:Merriam-Webster;2002.

26. Park MM, Park JW. Development of resilience scale for nurses. J Korean Acad Fundam Nurs 2016;23:32-41.

27. An YH, Suh SR. The effect of nurses' compassion competence on performance of terminal care in geriatric hospitals. J Health Info Stat 2019;44:253-61. 
28. Kim YK, Kwon S. Effects of empathy and attitude in caring for elders by nurses in geriatric nursing practice in long-term care hospitals. J Korean Gerontological Nurs 2017;19:203-13.

29. Palos GR. Care, compassion, and communication in professional nursing: art, science, or both. Clin J Oncol Nurs 2014;18:247-8.

30. Lee YJ. Development of the compassionate competence scale for nurses [dissertation]. Seoul: Korea Univ.; 2014. Korean. 